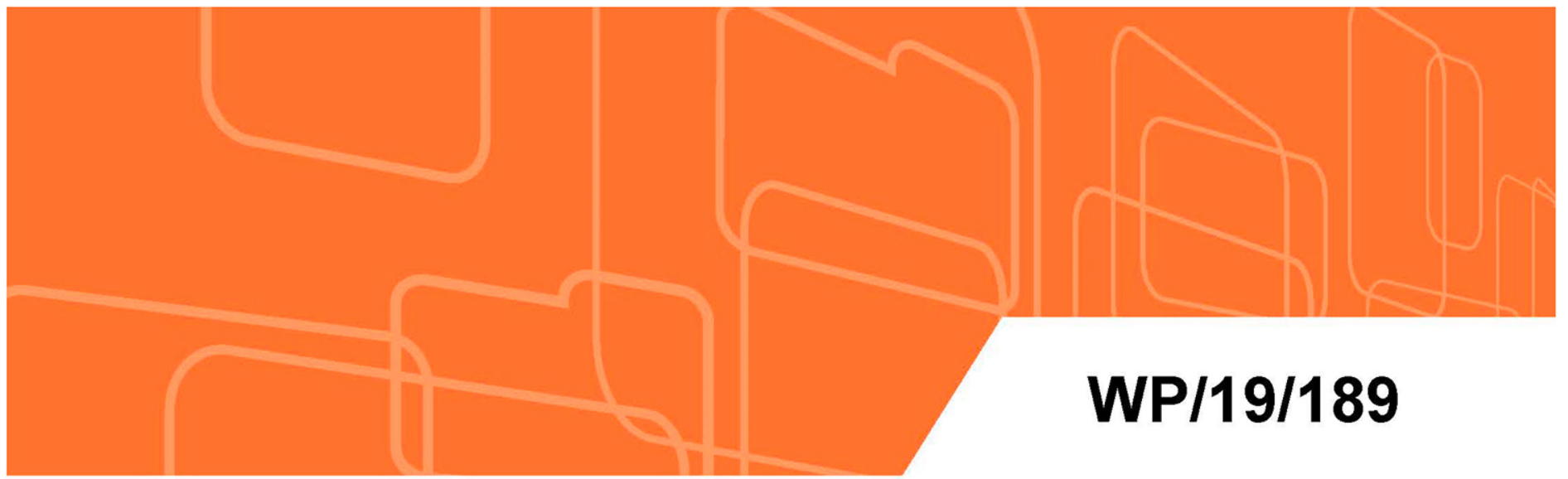

IMF Working Paper

\title{
Credit Misallocation and Economic Growth in Vietnam
}

by Mitsuru Katagiri

IMF Working Papers describe research in progress by the author(s) and are published to elicit comments and to encourage debate. The views expressed in IMF Working Papers are those of the author(s) and do not necessarily represent the views of the IMF, its Executive Board, or IMF management. 


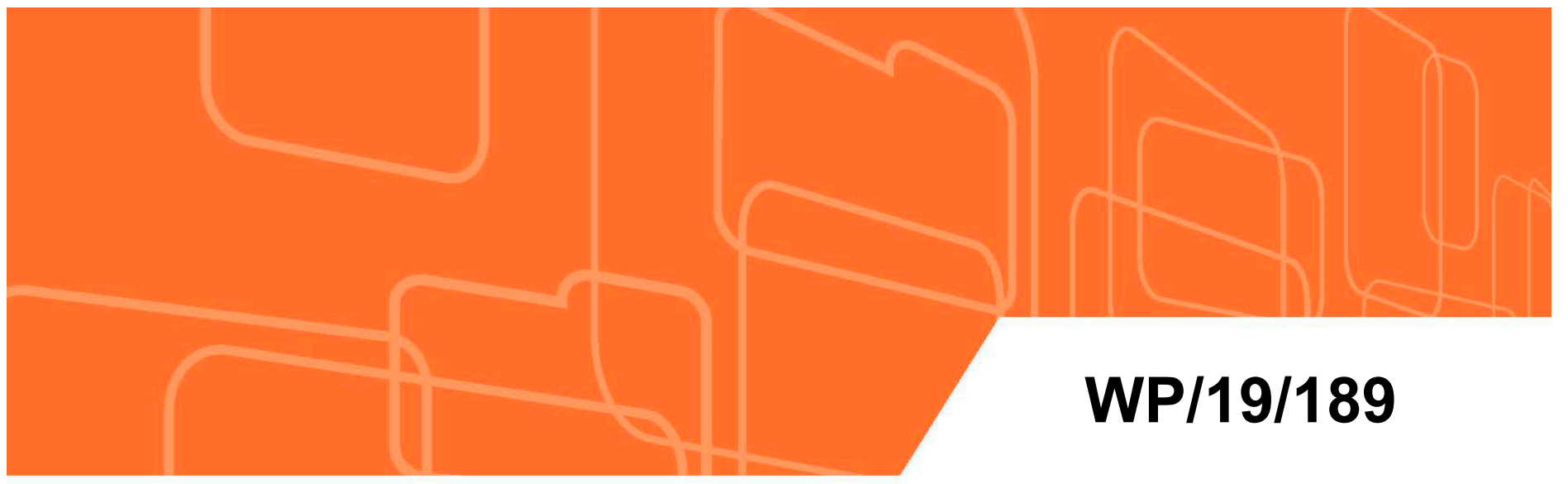

\title{
Credit Misallocation and Economic Growth in Vietnam
}

\author{
by Mitsuru Katagiri
}

IMF Working Papers describe research in progress by the author(s) and are published to elicit comments and to encourage debate. The views expressed in IMF Working Papers are those of the author(s) and do not necessarily represent the views of the IMF, its Executive Board, or IMF management. 


\title{
IMF Working Paper
}

Asia and Pacific Department

\section{Credit Misallocation and Economic Growth in Vietnam* \\ Prepared by Mitsuru Katagiri}

Authorized for distribution by Alexandros Mourmouras

June 2019

\section{IMF Working Papers describe research in progress by the author(s) and are published to elicit comments and to encourage debate. The views expressed in IMF Working Papers are those of the author(s) and do not necessarily represent the views of the IMF, its Executive Board, or IMF management.}

\begin{abstract}
The legacy of non-performing loans and high opportunity cost of government financing of bank recapitalization impeded the efficiency of financial intermediation and are an important policy issue in Vietnam. This paper presents a theoretical and empirical analysis of the issue. An empirical analysis using corporate data indicates credit misallocation between state owned enterprises and private firms in Vietnam. On the theoretical side, a micro-founded banking model is embedded in a political economy setting to assess the factors determining the size of bank recapitalization and its effects on the efficiency of financial intermediation, economic growth and welfare. The analysis suggests that recapitalization depends on an array of factors, including the tightness of the government budget and the decision maker's concern for the favored sector.
\end{abstract}

JEL Classification Numbers: E61, G21, H81

Keywords: credit misallocation, state owned enterprises, political economy

Author's E-Mail Address: mitsuru.katagiri@gmail.com

\footnotetext{
* The views expressed here are those of the author and do not necessarily represent the views of the IMF, its Executive Board, or IMF management. The author thanks the seminar participants at the IMF, the SBV and the 2017 Vietnam Symposium in Banking and Finance and additional seminars for valuable comments.
} 


\section{Table of Contents}

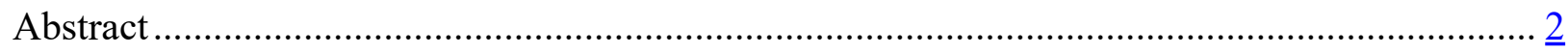

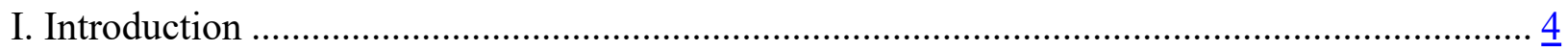

II. Motivating Facts: Credit Misallocation and SOEs in Vietnam............................................. $\underline{6}$

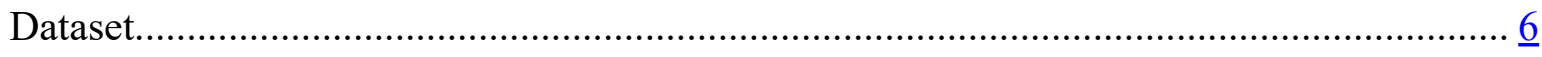

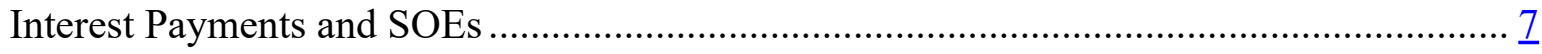

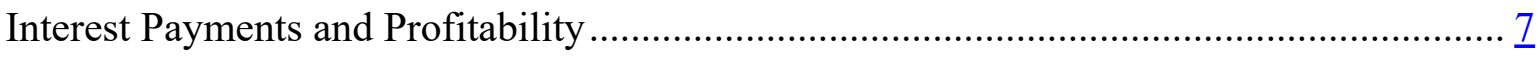

Loan Growth and Profitability ……………………………....................................... $\underline{8}$

III. Banking Model of Credit Misallocation ........................................................................... 9

A. Bank's Optimization and Equilibrium Behavior ………................................................ 10

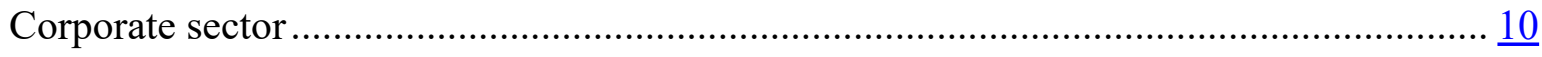

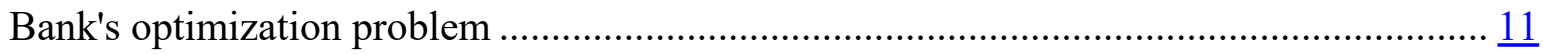

Optimal deposit rate, lending rate, and NPL resolution.................................................... 12

B. Policy Effects of Recapitalization ........................................................................... 13

The case of partial NPL resolution $(\mathbf{0} \leq \boldsymbol{x}<\mathbf{1}$, the second best $)$...................................... 14

The case of full NPL resolution $(\boldsymbol{x}=\mathbf{1}$, the first best).................................................... 15

C. Government Policy on Optimal Amount of Recapitalization ............................................ 17

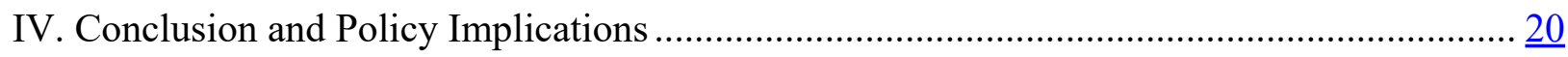




\section{INTRODUCTION}

Credit misallocation between private firms and state-owned enterprises (SOEs) and other favored firms has been an important obstacle for economic growth in many countries making the transition from plan to market. Politically connected firms are often able to access economic resources at preferential terms, including bank credit from state owned commercial banks and land use rights from provincial and local governments. The low interest rates and implicit or explicit governmental guarantees enjoyed by such firms squeeze the resources availablefor other more productive firms. Lower productive efficiency in SOEs and other connected firms results in resource misallocation that reduces aggregate productivity and economy-wide growth.

This paper examines the issue of resource misallocation between SOEs and non-SOEs in Vietnam from an empirical and theoretical point of view. This is a legacy issue as Vietnam's banking system has shifted in recent years to a new business model emphasizing lending to private households and firms, including mortgages and other consumer lending, and credit to private sector enterprises. But the legacy of lending to connected firms in Vietnam is felt in a large volume of legacy non-performing loans (NPLs) problem in the banking sector, an important part of which is to weak SOEs. ${ }^{1}$ In the theoretical part, credit misallocation in Vietnam is analyzed in a unified framework that considers the size of credit misallocation, thin capital buffers and NPL problem.

When considering the benefits for Vietnam from resolving credit misallocation, it is useful to consider other countries' experience. In China, several empirical studies suggest that aggregate productivity was suppressed by resource misallocation between SOEs and others until the 1990s. ${ }^{2}$ This changed in the late 1990s, when China restructured its SOEs and the associated NPL problems in the banking sector. Maliszewski et al. (2016) document that restructuring led to SOEs' share in urban employment dropping from 60 percent in 1994 to about a third in 2000. Even though millions of SOE workers were laid off and unemployment rose to double-digits during the restructuring period, long-term returns from resolving resource misallocation were high. Song, Storesletten, and Zilibotti (2011) construct a two-sector growth model and show that

\footnotetext{
${ }^{1}$ IMF (2013) emphasizes the relation between SOE lending and banking sector soundness.

${ }^{2}$ For example, Hsieh and Klenow (2009) use plant-level data over 1998-2005 and point out that 30-50\% of aggregate productivity gap between the U.S. and China is accounted for by credit misallocation across enterprises. Dollar and Wei (2007) find that capital returns are lower for SOEs in China, which implies credit misallocation between SOEs and others.
} 
the China's high economic growth from the 1990s can be mostly accounted for by the resolution of the credit misallocation problem. Hsieh and Klenow (2009) show that improvement in resource allocation raised Chinese TFP by 2 percent per year during 1998-2005.

International experiences also demonstrate the need for banks to have sufficient capital buffers to absorb credit losses, resolve their NPL problems and associated credit misallocation. Jobst et al. (2016) shows that European banks with lower capital adequacy ratios tended to choose smaller provisioning to NPLs. Peek and Rosengren (2005) show that undercapitalized banks in Japan tended to conduct forbearance lending, inducing credit misallocation. Gianetti and Simonov (2013) also take up the case of Japan. They show that if recapitalization by public funds is large enough to reestablish banks' capital buffers, it helps recover their credit supply. Finally, Ma (2006) points out that bank recapitalization by public funds was a necessary part of the Chinese SOEs reform and NPL resolution in the 1990s.

With this international experience as background, this paper provides an empirical and theoretical analysis on forbearance lending, credit misallocation, and economic growth in Vietnam. In the empirical analysis, we use corporate data in Vietnam compiled by Worldscope from 2005 to 2015. The following empirical results are obtained by means of panel regressions: (i) SOEs obtain bank credit at lower cost on average even after controlling for firm characteristics such as profitability and size, (ii) while lending rates and credit growth are positively correlated with ex-ante profitability for non-SOEs, they are almost unrelated to exante profitability in underperforming SOEs. The two results imply that commercial banks keep lending to underperforming SOEs at artificially low lending rates. In the theoretical part, we present a simple two-sector banking model, emphasizing the importance of capital buffers in resolving the NPL problem and associated credit misallocation. After establishing the equilibrium in a banking sector, we present a simple political economy model in which the government selects the size of bank recapitalization.

The rest of paper proceeds as follows. Section 2 provides motivating facts based on panel regressions using Vietnamese corporate data. In Section 3, a simple banking model based on bank profit maximization is presented that clarifies the importance of credit misallocation for productivity and output and the importance of capital buffers for resolving NPL problems. Then, I nthe second stage, we examine the government's incentive to carry out recapitalization to achieve the first best outcome from a political economy viewpoint. Concluding remarks and some policy implications are provided in Section 4. 


\section{Motivating Facts: CRedit Misallocation and SOEs in Vietnam}

This section examines credit misallocation between SOEs and non-SOEs in Vietnam by the following three regression analyses using corporate data for Vietnam's listed firms. The first regression analysis examines whether SOEs obtain bank credit at lower cost compared with nonSOEs. Then, the second regression analysis investigates the relationship between interest payments and profitability to examine whether underperforming SOEs obtain bank credit at unreasonably low rates. Finally, the third regression analysis investigates the relationship between debt growth and profitability to examine whether underperforming SOEs continue to obtain bank credit regardless of their performances.

\section{Dataset}

The dataset is annual unbalanced panel data taken from Worldscope, which contains all listed firms' financial data during 2005-2015. ${ }^{3}$ For regression analysis, the corporate financial variables are defined as follows.

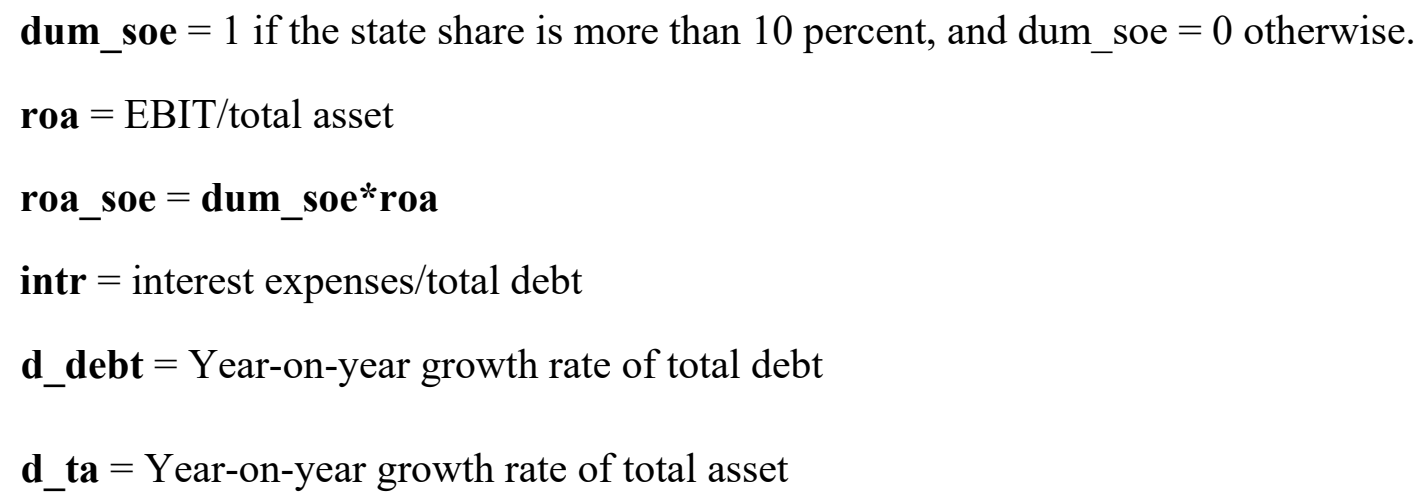

Then, the dataset is cleaned by dropping outliers and some industries. First, data for the industries of Telecommunications, Utilities, and Financials (ICB: 6000-9000) are dropped from the sample because their financial strategy is significantly different from others. Second, if the sample hits at least one of the following criteria, it is dropped as an outlier. (1) roa is more than 99-percentile or less than 1-percentile. Then, roa is in [-0.17, 0.38], (2) intr is negative or more than 40 percent, (3) d_debt is more than 100 percent, (4) d_ta is more than 50 percent.

\footnotetext{
${ }^{3}$ Since the dataset contains only listed firms, fully state owned enterprises are not included. Hence, credit misallocation between SOEs and non-SOEs is probably more pervasive in reality than shown in this section.
} 


\section{Interest Payments and SOEs}

First, I investigate the differences in loan rates between SOEs and non-SOEs after controlling for firm characteristics by,

$$
\text { int }_{\mathbf{i}, \mathbf{t}}=\beta_{0}+\beta_{1} \text { dum_soe }_{\mathbf{i}}+\text { controls }_{\mathrm{i}, \mathrm{t}} .
$$

The control variables include $\mathbf{r o a}_{\mathbf{t}-\mathbf{1}}, \mathbf{r o a}_{\mathbf{t}}$, and $\log$ of total assets. The estimation result shows that $\beta_{1}=-0.0044$ ( $t$ value: -2.30 ), suggesting that SOEs obtain credit at lower rates on average even after controlling for profitability and firm size.

\section{Interest Payments and Profitability}

Second, to examine whether loan rates are lower for SOEs at the ex-ante and/or ex-post stage, the relationship between loan rates and profitability is investigated by,

$$
\text { int }_{\mathbf{i}, \mathbf{t}}=\beta_{0, \mathbf{i}}+\beta_{1} \text { roa }_{\mathbf{i}, \mathbf{t}-\mathbf{1}}+\beta_{2} \text { roa }_{\mathbf{i}, \mathbf{t}}+\beta_{3} \text { roa_soe }_{\mathbf{i}, \mathbf{t}-\mathbf{1}}+\beta_{4} \text { roa_soe }_{\mathbf{i}, \mathbf{t}}+\text { controls }
$$

The control variables include log of total assets, the growth rate of total asset, and year dummies. ${ }^{4}$ Also, fixed effects for each firm are included. In this regression, while the average sensitivity of interest payments to ex-ante and ex-post profitability are captured by $\beta_{1}$ and $\beta_{2}$, those for SOEs are captured by $\beta_{1}+\beta_{3}$ and $\beta_{2}+\beta_{4}$. Hence, if SOEs obtain bank credit at lower

\begin{tabular}{|c|c|c|c|}
\hline $\begin{array}{r}\text { Ta } \\
\text { Dependent Var }\end{array}$ & $\begin{array}{l}\text { e 1. Vietnam: I } \\
\text { ble: inter }\end{array}$ & in rates and profit & ability \\
\hline & all firms & $\begin{array}{c}\text { good firms } \\
\text { (above median) }\end{array}$ & $\begin{array}{c}\text { bad firms } \\
\text { (below median) }\end{array}$ \\
\hline roa $_{t-1}$ & $-0.064 * * *$ & $-0.154 * * *$ & $-0.111^{*}$ \\
\hline $\mathrm{roa}_{\mathrm{t}}$ & $0.148^{* * *}$ & $0.216^{* * *}$ & $0.105^{* *}$ \\
\hline roa_soe ${ }_{t-1}$ & 0.015 & 0.030 & $0.183^{* *}$ \\
\hline roa_soe ${ }_{t}$ & 0.050 & -0.043 & 0.069 \\
\hline
\end{tabular}
rates, we would have $\beta_{3}>0$ (ex-ante) and/or $\beta_{4}>0$ (ex-post). In addition to the estimation

\footnotetext{
${ }^{4}$ While the maturity and the credit risk of firms also have effects on the interest rates, those variables are not included in the control variables due to data constraints. A part of their effects, however, are captured by the fixed effect for each firm in the panel regression.
} 
using a whole sample, the sub-sample estimation for "good firms" (firms with ROA higher than the median) and "bad firms" (firms with ROA lower than the median) are also provided to examine whether the relationship between loan rates and profitability for good firms is different from that for bad firms.

Table 1 shows the estimation results for the full sample regression as well as the sub-sample regressions. For all regressions, the relationship between loan rates and profitability is negative for the ex-ante stage (i.e., $\beta_{1}<0$ ), but it is positive for the ex-post stage (i.e., $\beta_{2}>0$ ). These estimation results are intuitive, because they imply that banks lend profitable firms at lower rates in the ex-ate stage, while banks provide a kind of interest payment forgiveness to unprofitable firms in the ex-post stage to financially support a temporarily unprofitable firm.

A noteworthy result in Table 1 is that unprofitable SOEs obtain credit at lower rates in the exante stage. While the relationship between loan rates and profitability is negative on average (i.e., $\beta_{1}<0$ ), this relationship for unprofitable SOEs (SOEs in the bad firm sample) is significantly biased to positive $\left(\beta_{3}=0.183\right)$ and there is no clear relationship between loan rates and profitability for SOEs (i.e., $\beta_{1}+\beta_{3}$ is close to zero), suggesting that underperforming SOEs obtain loans at lower loan rates compared with non-SOEs.

\section{Loan Growth and Profitability}

Finally, this subsection examines the relationship between loan growth and profitability. If underperforming SOEs obtain forbearance lending from banks, the relationship between loan growth and ex-ante profitability, which normally has positive correlation, would be negatively biased and become ambiguous for SOEs. To examine this hypothesis, we run the panel regression with fixed effects,

$$
\text { d_debt }_{\mathbf{i}, \mathbf{t}}=\beta_{0, \mathbf{i}}+\beta_{1} \text { roa }_{\mathbf{i}, \mathbf{t}-\mathbf{1}}+\beta_{2} \text { roa_soe }_{\mathbf{i}, \mathbf{t}-\mathbf{1}}+\text { control. }
$$

The control variables include total asset and year dummies. In this specification, the sensitivity of debt growth to profitability is captured by $\beta_{1}$ for all firms on average and by $\beta_{1}+\beta_{2}$ for SOEs. Hence, if the forbearance lending to SOEs exists, we will have $\beta_{2}<0$.

Table 2 shows the estimation result for the relationship between loan growth and profitability. The table shows that the relationship is clearly positive on average (i.e., $\beta_{1}>0$ ) for the whole sample estimation as well as the subsample estimation, implying that profitable firms increase their debt to expand their businesses while unprofitable ones decrease their debt to shrink their businesses. However, for SOEs (particularly for SOEs in the bad firm sample), this relationship 
is biased to negative compared with non-SOEs (i.e., $\beta_{2}<0$ ), and there is no clear relationship between loan growth and profitability for SOEs (i.e., $\beta_{1}+\beta_{2}$ is close to zero), implying that some SOEs obtain forbearance lending even with their underperforming profitability.

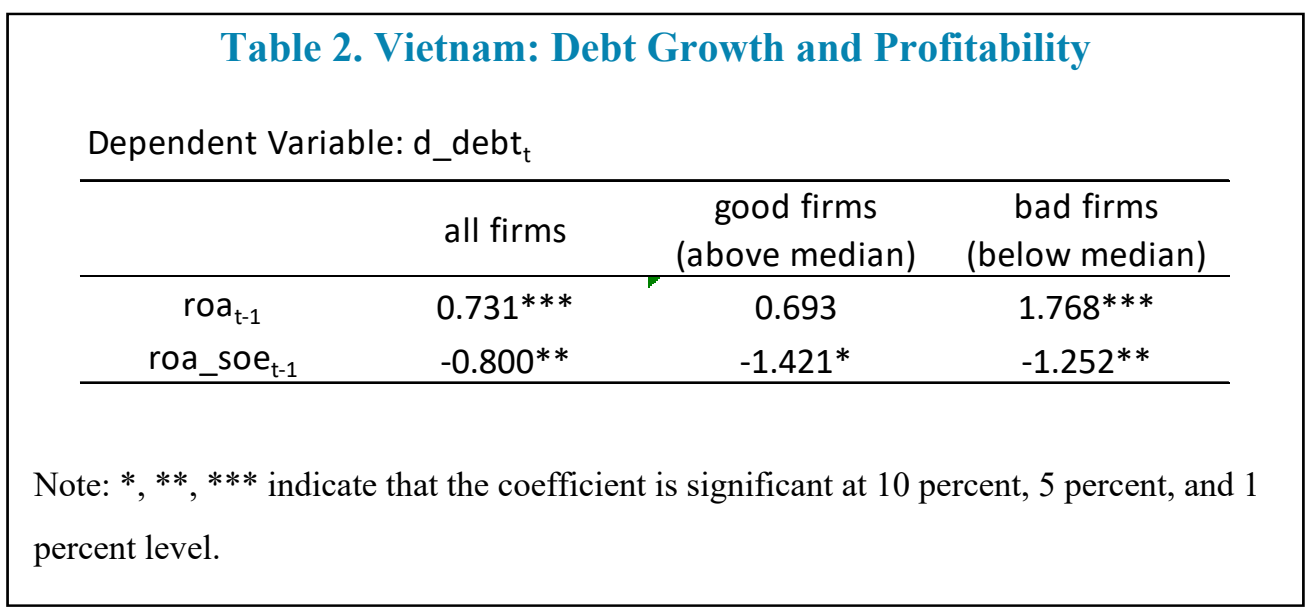

In sum, the estimation analyses indicate that: (i) SOEs obtain bank credit at lower costs on average even after controlling for firm characteristics such as profitability and size, (ii) while lending rates and loan growth are positively correlated with ex-ante profitability on average, those for underperforming SOEs are almost unrelated to ex-ante profitability. The second result combined with the first result implies that commercial banks keep lending to unprofitable SOEs at unreasonably low lending rates. Based on these motivating facts, the following section provides with a simple banking model to investigate macroeconomic implications of the credit misallocation between SOEs and non-SOEs and analyzes how the recapitalization policy helps banks resolve the credit misallocation problem. Then, the banking model is incorporated into the political economy context in order to identify what factors determine the amount and speed of recapitalization using public funds.

\section{Banking Model of Credit Misallocation}

Based on the motivating facts described in the previous section, this section proposes a simple two-sector banking model to understand the causes and consequences of credit misallocation. The model is an extension of the Monti-Klein model, where a representative bank has monopolistic powers in lending and deposit markets, by putting particular emphasis on the importance of bank capital buffer to resolve the NPL problem and associated credit misallocation..$^{5}$ After establishing the equilibrium in a banking sector, we investigate the

\footnotetext{
${ }^{5}$ See, for example, the chapter 3 in Freixas and Rochet (2008) for the prototype Monti-Klein model.
} 
government policy on bank recapitalization from a political economy perspective to understand what is the main constraint for the resolution of NPL problems through bank recapitalization.

\section{A. Bank's Optimization and Equilibrium Behavior}

\section{Corporate Sector}

Production takes place in two sectors, a high-productivity sector ( $\mathrm{H}$ sector) and a lowproductivity sector (L sector), and requires working capital financed by bank credit. In each sector $i=h, l$, firms have production functions,

$$
y_{h}=z_{h} k_{h}^{\theta} \text { and } y_{l}=z_{l} k_{l}
$$

where $y_{i}$ is output, $k_{i}$ is the amount of capital (i.e., credit), and $z_{i}$ is productivity satisfying $z_{l}<$ $z_{h}$. While the H sector's production function is assumed to be decreasing return to scale, $\theta<1$, as in a standard model, the L sector's production function is assumed to be linear. The economic intuition behind this different specification across sectors is that the H sector's firms possess high return projects but their return would become lower as the size of firm becomes bigger due to the scarcity of the high return projects. The L sector's firms, on the other hand, cannot access to such high return projects and just do abundant but low return projects. We think of the L sector as representing inefficient and lower productivity SOEs recognized as a stock of legacy NPLs at the loan book. The profit maximization by firms in each sector is formulated as

$$
\max _{k_{h}} z_{h} k_{h}^{\theta}-R_{L, h} k_{h} \text { and } \max _{k_{l}} z_{l} k_{l}-R_{L, l} k_{l}
$$

where $R_{L, h}$ and $R_{L, l}$ are lending rates in each sector.

The first order conditions for firms gives the following loan demand functions in the $\mathrm{H}$ and $\mathrm{L}$ sector.

$$
k_{h}=\left(\frac{R_{L, h}}{\theta z_{h}}\right)^{\frac{1}{\theta-1}} \text { and } R_{L, l}=z_{l}
$$

These loan demand functions are treated as given for banks when they optimally choose their lending rates in the $\mathrm{H}$ and $\mathrm{L}$ sector. 


\section{Bank's Optimization Problem}

A representative bank lends to firms and invests in riskless bonds by funding through their own equity and deposits. The bank's balance sheet is:

$$
k_{h}+k_{l}+b=d+e
$$

where $b$ is bonds, $d$ is deposits, and $e$ is equity. The bond gives the riskless market return, $R_{M}$, which is exogenous in the model.

Given the initial amount of credit to the L sector (i.e., the legacy of NPLs), $\bar{k}_{l}$, the bank chooses the amount of NPLs resolved in this period. In what follows, we use the amount of NPLs and the amount of credit to the $\mathrm{L}$ sector interchangeably. The law of motion for $k_{l}$ becomes,

$$
k_{l}=(1-x) \bar{k}_{l}
$$

where $x$ is the fraction of NPLs resolved, which is the bank's choice variable. The resolution of NPLs incurs loan impairment costs and erodes the bank's equity,

$$
e=\bar{e}-\phi x \bar{k}_{l}
$$

where $0 \leq \phi \leq 1$ is the loss given default (LGD) for NPLs. The initial value of capital, $\bar{e}$, consists of the equity which the bank accumulated until the current period, $e^{B}$, and the capital injected by the government, $e^{G}$. That is, $\bar{e}=e^{B}+e^{G}$, and the bank takes $\bar{e}$ as being beyond its control when it solves the optimization problem. The supply of deposits is determined by the following deposit supply function,

$$
d=\bar{d} R_{D}^{\epsilon}
$$

where $R_{D}$ is the deposit rate and $\epsilon>0$ is the elasticity of deposit supply.

The bank optimally chooses deposit and lending rates as well as the amount of NPL resolution under several constraints including the capital constraint. More formally speaking, the bank maximizes the profit,

$$
\pi=R_{L, h} k_{h}+R_{L, l} k_{l}+R_{M} b-R_{D} d
$$


by choosing $R_{L, h}, R_{L, l}, R_{d}, b$, and $x$, subject to (i) the law of motions for $k_{l}$ and $e$ given the initial amount of NPLs, $\bar{k}_{l}$, and equity, $\bar{e}=e^{B}+e^{G}$ [eq. (3) and eq. (4)], (ii) the budget constraint [eq. (2)], (iii) the deposit supply function [eq. (5)], (iv) the loan demand functions in each sector [eq. (1)], and (v) the capital requirement,

$$
e \geq \gamma d
$$

which indicates that the equity-to-debt ratio must be higher than $\gamma$.

\section{Optimal Deposit rate, Lending Rate, and NPL Resolution}

The optimality conditions for the bank's maximization problem give the bank's optimal choice of lending rate, deposit rate, and the amount of NPL resolution. First, the optimal deposit rate is,

$$
R_{D}^{*}=\frac{\epsilon}{1+\epsilon} R_{M}
$$

where $\epsilon /(1+\epsilon)<1$ is a mark-down for deposit rates. Second, the optimal lending rates in each sector become,

$$
R_{L, h}^{*}=\frac{R_{M}+\gamma \lambda}{\theta} \text { and } R_{L, l}^{*}=z_{l}
$$

where $\lambda$ is a Lagrange multiplier for the capital constraint. Note that the lending rate for the $\mathrm{H}$ sector, $R_{L, h}^{*}$, would be higher when the capital constraint binds (i.e., $\lambda>0$ ). Since the higher lending rate means the lower credit supply to the H sector, this result implies that the bank's undercapitalization leads to credit misallocation across the two sectors because banks facing undercapitalization squeeze lending to the $\mathrm{H}$ sector to meet the capital constraint. When the capital constraint does not bind, the lending rate is equal to the riskless rate $R_{M}$ times the optimal mark-up $1 / \theta$. Finally, the optimal amount of NPL resolution in equilibrium, $x^{*}$, is determined as,

$$
x^{*}=\frac{e^{G}+e^{B}-\gamma\left(k_{h}^{*}+\bar{k}_{l}\right)}{(\phi-\gamma) \bar{k}_{l}} \leq 1
$$

where $k_{k}^{*}=\left(\frac{R_{L, h}^{*}}{\theta z_{h}}\right)^{\frac{1}{\theta-1}}$ and $R_{L, h}^{*}=\frac{R_{M}+\gamma \lambda}{\theta}$. A noteworthy point here is that the equilibrium value of $x^{*}$ is an increasing function of the capital injection by the government, $e^{G}$. This is because, given the capital constraint, the bank needs enough capital buffers, $e^{B}+e^{G}$, to absorb the credit losses 
induced by NPL resolution. Without enough capital buffers, the bank does not resolve NPLs aggressively because the NPL resolution would cause a serious capital shortage and consequently force the bank to substantially reduce the amount of credit to meet the capital requirement. Hence, the above equilibrium behavior for $x^{*}$ implies that the capital injection by the government can help the bank resolve more NPLs and the associated capital misallocation problem, as investigated in the following comparative statics.

\section{B. Policy Effects of Recapitalization}

Given the bank's optimal behavior in equilibrium, this subsection analyzes the policy effects of recapitalization policy, $e^{G}$, by comparative statics. The government's recapitalization policy is evaluated by macroeconomic performance and bank's profitability measures. First, the aggregate output, $Y$, and the aggregate productivity, $Z$, are defined as

$$
Y=y_{h}+y_{l}=z_{h} k_{h}+z_{l} k_{l}
$$

and

$$
Z=\frac{y_{h}+y_{l}}{k_{h}+k_{l}}
$$

Note that the aggregate productivity would be increased if bank credit is more allocated to the $\mathrm{H}$ sector because $z_{h}>z_{l}$. In other words, credit misallocation across the two sectors lowers the aggregate output via decreasing the aggregate productivity, $Z$. Second, the bank's profitability is measured by the following net interest margin (NIM) for loans and deposits,

$$
N I M=\frac{R_{L . h} k_{h}+R_{L, l} k_{l}}{k_{h}+k_{l}}-R_{D .}
$$

We investigate macroeconomic consequences of credit misallocation by evaluating the effects on those macroeconomic variables through comparative statics.

To quantify the result of comparative statics, the model parameters are calibrated as follows. The minimum requirement for capital ratios is set to 9 percent, which means $\gamma=0.1$, and LGD is 30 percent, $\phi=0.3$. The NPL in the initial period, $\bar{k}_{l}$, is chosen so that the NPL ratio is equal to 12 percent. Both the market return $R_{M}$ and the productivity in the good sector $z_{h}$ are set to 1.06 (i.e., 6 percent) based on the average growth rate in Vietnam. The elasticity of deposit demand $\epsilon$ and the curvature of production function $\theta$ are chosen so that the deposit and lending rate are equal to 5 percent and 9 percent, respectively. The most important and difficult parameter to be set is the 
return in the bad sector $z_{l}$. We set $z_{l}=0.7$ for illustration, but note that while the quantitative result would depend on the value of $z_{l}$, the qualitative implication does not change. Finally, the initial value of equity, $\bar{e}$, is chosen so that the resolution of NPLs is 20 percent without capital injection, $e^{G}=0$.

Figure 1-1 shows the equilibrium amount of NPL resolution, $x^{*}$, with respect to the government's capital injection, $e^{G}$. The figure indicates that as the government injects more capital into the bank, the bank tends to resolve more NPLs. As is mentioned in the previous subsection, this equilibrium relationship between the bank's capital buffer and the amount of NPL resolution implies that the government can facilitate the bank's NPL resolution through increasing recapitalization by public funds, $e^{G}$. Since the full NPL resolution $(x=1)$ would be realized at some point as the recapitalization by the government, $e^{G}$, continues, we will discuss the policy implications of recapitalization separately between (i) the second-best case (i.e., partial NPL resolution, $0 \leq x<1$ ), and (ii) the first-best case (i.e., full NPL resolution, $x=1$ ). ${ }^{6}$

\section{The Case of Partial NPL Resolution $(0 \leq x<1$, the second best)}

In the partial NPL resolution case (i.e., $0 \leq x<1$ ), credit misallocation still entails some growth cost by lowering aggregate productivity. Since the banking sector is still undercapitalized in this case, it cannot resolve all NPLs. The equilibrium amount of credit supply to the H sector (blue) and the L sector (orange), which is shown in Figure 1-2, indicates that the credit supply to the L sector proportionally decreases as the bank's capital buffers increase, because more capital buffers enable the bank to resolve more NPLs (= reduce the loan supply to the L sector). In the second-best case, however, some firms in the L sector still continue operating thanks to forbearance lending. Given the fact that $z_{h}>z_{l}$, this result implies that as long as undercapitalization continues to exist, credit misallocation lowers aggregate productivity compared with the case of full NPL resolution.

Figure 1-2 also shows that, the amount of credit supply to the $\mathrm{H}$ sector would be unchanged unless NPLs are fully resolved. In the model, when $0 \leq x<1$, the Lagrange multiplier for the capital constraint is constant at,

$$
\lambda=\frac{R_{M}(1-\phi)-z_{l}}{\phi-\gamma}>0 .
$$

\footnotetext{
${ }^{6}$ There is also no NPL resolution case (i.e., $x=0$ ), where the bank does not resolve any NPLs because its capital buffer is very thin. This case is, however, so extreme that we do not consider it hereafter.
} 
Therefore, the equilibrium lending rate and the amount of credit supply to the $\mathrm{H}$ sector are also constant with respect to $e^{G}$. Intuitively, this result implies that if the bank still holds NPLs in its balance sheet, the bank wants to use as much capital buffer as possible to absorb the credit losses incurred by NPL resolution. Hence, the bank refrains increasing the credit supply to the $\mathrm{H}$ sector, because increasing credit supply requires the bank to hold more capital in order to keep the required level of capital and decreases its capital buffer to be used for NPL resolution.

Figure 1-3 shows that aggregate output, $Y$, is slightly decreasing in the process of recapitalization. This result simply comes from the fact that the bank decreases their credit supply to the L sector in the process of reducing NPLs, while it does not increase their credit supply to the $\mathrm{H}$ sector, thus reducing the total amount of credit in a whole economy. Intuitively, this result can be interpreted that the economy would experience a temporary economic downturn due to an adjustment process of NPL resolution before the economy enjoys the longterm returns of resolving credit misallocation. This theoretical result is consistent with an analysis on other countries with resource misallocation problem. For example, IMF (2016) shows an illustrative scenario with a proactive government strategy in terms of SOE reforms in China, and concludes that the proactive strategy would entail short-term costs but induce longerterm gains by normalizing resource reallocation.

Finally, Figure 1-4 shows that the NIM would increase as recapitalization of banking sector proceeds. In the process of recapitalization, while deposit rates are constant, the bank's asset return is increasing on average due to the improvement of credit allocation across the two sectors. That is, when the bank has enough capital buffers, it improves its profitability by reallocating its loan supply from the $\mathrm{L}$ sector to the $\mathrm{H}$ sector. Since the profitability is a key factor to attract outside investors, this result implies that recapitalization is possibly effective to attract new equity including foreign investors by raising profitability measures.

\section{The Case of Full NPL Resolution ( $x=1$, the first best)}

As is clear from Figure 1-1, the full NPL resolution $(x=1)$ would be realized at some point as recapitalization by public funds, $e^{G}$, increases. In the case of full NPL resolution, a complete shutdown of credit to the $\mathrm{L}$ sector is realized, because the bank fully recognizes and resolves NPLs with full bank recapitalization and no capital scarcity. There are two subcases in the first best case. The first subcase is that NPLs are fully resolved but the capital constraint still binds (i.e., $x=1$ and $\lambda>0$ ), and the second subcase is that NPLs are fully resolved and the capital constraint is slack due to ample capital buffers (i.e., $x=1$ and $\lambda=0$ ). 
About the credit allocation across sectors, Figure 1-2 indicates that after completing the NPL resolution, bank credit to the $\mathrm{H}$ sector would start to increase along with recapitalization. When the economy reaches $x=1$, the Lagrange multiplier becomes,

$$
\lambda=\frac{\theta^{2} z_{h}}{\gamma^{\theta}\left(e^{G}+e^{B}-\phi \bar{k}_{l}\right)^{1-\theta}}-\frac{R_{M}}{\gamma},
$$

which is obviously a decreasing function of $e^{G}$. Hence, given the fact that the equilibrium lending rate to the $\mathrm{H}$ sector, $R_{L, h}^{*}$, is decreasing with respect to $\lambda$, the credit supply to the $\mathrm{H}$ sector, $k_{h}$, would be increasing with respect to $e^{G}$. Intuitively, this result indicates that once the bank completes its NPL resolution, it does not have to use its capital buffer for absorbing the credit losses incurred by NPL resolution, and so utilizes the capital buffer for extending new loans to productive firms in the $\mathrm{H}$ sector. Because of the decline in lending rate, $R_{L, h}^{*}$, the bank's profitability measured by NIM would start to decline along with recapitalization, which suggests that the bank's NIM could be slightly inflated when the bank is undercapitalized and so squeezes loans to the corporate sector (Figure 1-4).

Figure 1: Policy Effects of Recapitalization
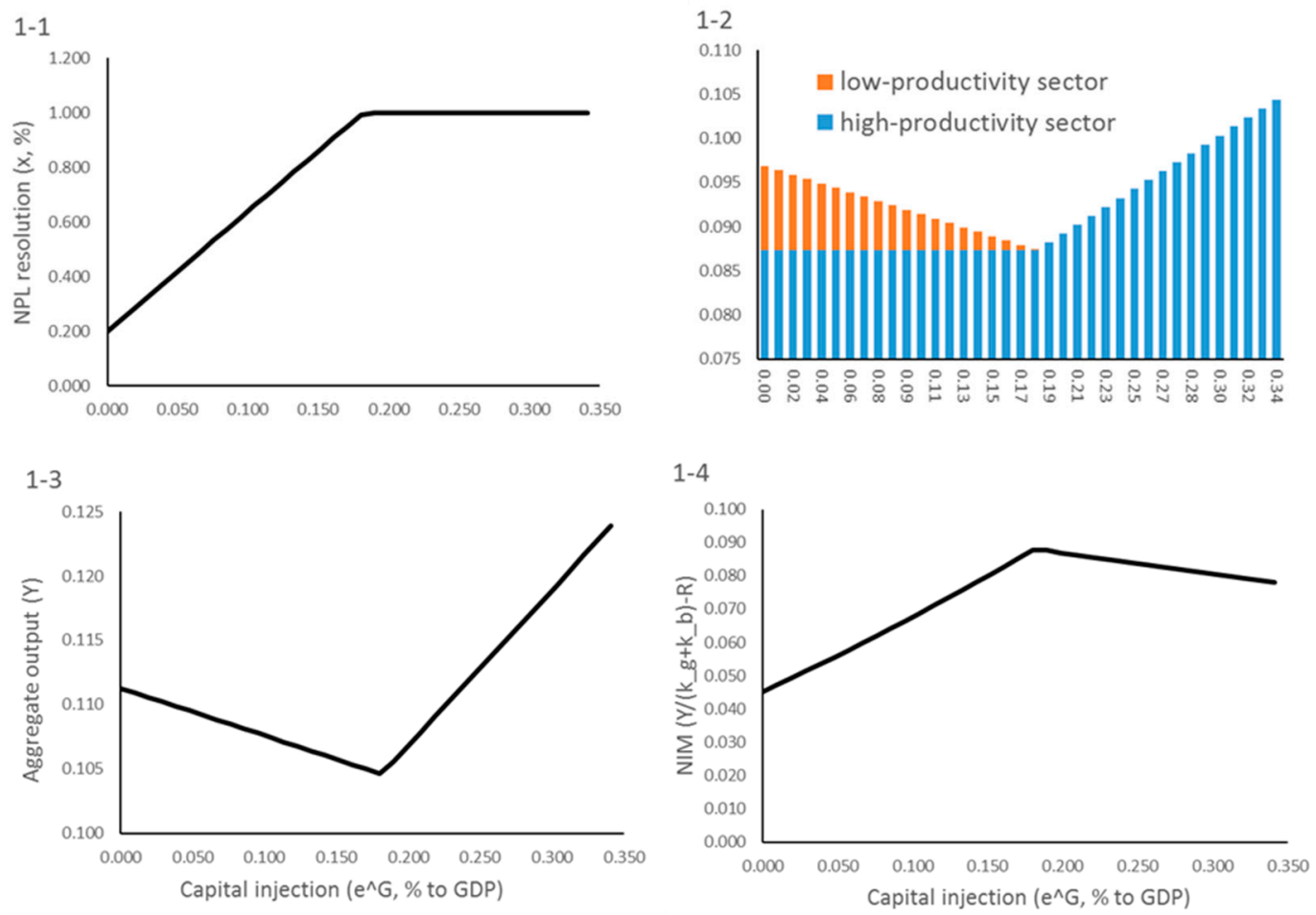
On the back of the increase in credit supply to the $\mathrm{H}$ sector, the aggregate output $Y$ starts to increase along with recapitalization, after the bank has completed its NPL resolution (Figure 13). Since $Y$ is slightly decreasing with respect to $e^{G}$ when $x<1$, the response of $Y$ to $e^{G}$ becomes a $\mathrm{V}$-shaped function with respect to $e^{G}$, which is kinked at $x=1$, as shown in Figure 13. Hence, since the $\mathrm{V}$-shaped function is mainly formed by the $\mathrm{V}$-shaped response of total amount of credit shown in Figure 1-2, this result implies that undercapitalization in the banking sector suppresses economic growth not only due to the too much lending to the L sector but also due to the too little credit supply to productive firms.

Although it is not shown in the figures, the capital injection becomes ineffective and does not boost output eventually, as the capital constraint becomes slack due to ample capital buffers at some point. In this case, since the Lagrange multiplier $\lambda$ is constant at zero, all variables including lending rates, the amount of credit, output, and profitability measures are all constant with respect to $e^{G}$. In the following analysis from the political economy viewpoint, the case of slack capital constraint (i.e., $x=1$ and $\lambda=0$ ) will be excluded from the analysis, because it is unrealistic for the government to inject huge amount of capital into the banking sector so that the capital constraint becomes slack for banks. Hence, the "full capitalization case" in the following section means the case that NPLs are fully resolved but the capital constraint still binds (i.e., $x=$ 1 and $\lambda>0)$.

\section{Recapitalization: The Political Equilibrium}

In the previous subsection, the amount of recapitalization by public fund, $e^{G}$, was treated as exogenous variable. However, in the real economy, this variable is endogenously determined by the government. In this subsection, the government's optimal decision on the amount of recapitalization is modeled as a political economy equilibrium. Based on the equilibrium in a banking model described in the previous section, the process of policy making is formulated as a two-stage game between the government and the bank: the government optimally chooses the amount of $e^{G}$ in the first stage by predicting the reactions by the bank in the second stage, then the bank makes its optimal decision in the second stage by taking the amount of $e^{G}$ as given.

In this exercise, the government budget constraint is formulated as,

$$
T=e^{G}+G,
$$


where $T$ is the (fixed) tax revenue, $e^{G}$ is the amount of expenditure for recapitalization, and $G$ is other government expenditures. Then, the government solves its optimization problem by a backward induction: Given the above budget constraint as well as the bank's optimal reactions in the second stage, the government decides on the amount of recapitalization $e^{G}$ in the first stage to maximize the social welfare function,

$$
U=Y+\alpha y_{l}+\beta f(G)
$$

Here, $Y$ is the aggregate output, $y_{l}$ is the output in the L sector, and $f(G)$ is the social welfare from other government expenditures, which satisfies $f^{\prime}(\cdot)>0, f^{\prime \prime}(\cdot)<0$, and $f^{\prime}(\underline{G})=\infty$ where $\underline{G} \geq 0$. The parameters $\alpha$ and $\beta$, which represent the relative importance of $y_{l}$ and $f(G)$ in the social welfare, are interpreted that: (i) a high $\alpha$ means that the government has a special interest to support firms in the L sector, namely SOEs and other favored enterprises, ${ }^{7}$ and (ii) a high $\beta$ means that the government considers other government expenditures (infrastructure, social security, education, etc.) as important expenses for the country's social welfare. Hence, these two parameters, $\alpha$ and $\beta$, are key parameters to understand the government policy behaviors in the equilibrium.

The optimal amount of recapitalization can be characterized into either of the following two cases: (i) zero capitalization ( $e^{G}=0$ ), or (ii) positive capitalization ( $e^{G}>0$ ). The cases (i) is characterized as a corner solution while the case (ii) is characterized as an inner solution where the first order condition $\partial U / \partial e^{G}=0$ is satisfied. ${ }^{8}$ In the first case, the government decides not to use public funds for recapitalization because the fiscal cost of recapitalization is larger than its benefit, which is close to the current situation in Vietnam. In the second case, the marginal fiscal cost of recapitalization is equal to its marginal benefit to the social welfare.

\footnotetext{
${ }^{7}$ Here, it is taken as given that the government has special interests on SOEs or other favored enterprises. Grossman and Helpman (2001) gives more detailed stories behind such a special treatment to a specific group.

${ }^{8}$ The second case possibly has another type of corner solution associated with capital constraint, namely $\lambda=0$. In this case, the government inject huge amount of capital into the bank so that the capital constraint becomes slack. As is explained in the previous section, since this case is unrealistic from the public policy perspective, it is excluded from the analysis of the optimal government policy and assumed that the capital constraint is always binding in this subsection.
} 
Technically, the government's optimal choice is computed by the following sequential procedure. First, suppose that the government's optimal choice has an inner solution and try to compute $e^{G}$ which satisfies the following first order condition (FoC),

$$
\frac{\partial U}{\partial e^{G}} \equiv \frac{\partial Y}{\partial e^{G}}+\alpha \frac{\partial y_{l}}{\partial e^{G}}-\beta f^{\prime}\left(T-e^{G}\right)=0
$$

and defines the value of $e^{G}$ satisfying the FoC as $e^{G *}$. If $e^{G}$ satisfying the above FoC cannot be computed because $\partial U / \partial e^{G}<0$ for all $e^{G} \geq 0$, then the government's optimal choice has a corner solution of zero recapitalization, $e^{G}=0$. Intuitively, $\partial U / \partial e^{G}<0$ for all $e^{G} \geq 0$ implies that the marginal benefit of recapitalization is always smaller than the marginal fiscal cost of cutting other government expenditures, thus the government have no incentive to recapitalize the banking sector. ${ }^{9}$ When the $\mathrm{FoC}$ is satisfied at some $e^{G *}>0$, then the following claim is satisfied.

Claim. If $e^{G *}$ satisfies the FoC of the government optimization problem, then the bank will resolve all NPLs (i.e., $x^{*}=1$ ) under $e^{G}=e^{G *}$ in the second stage of the game.

The logic behind this claim is simple. When $x<1$, the marginal benefit of recapitalization, $\partial U / \partial e^{G}$, is always negative because all terms in the $\mathrm{FoC}$ are negative due to the $\mathrm{V}$-shape response of output shown in Figure 1-3. Intuitively, this result implies that any halfway recapitalization is never optimal for the government because it does not induce any credit reallocation from the $\mathrm{L}$ sector to the $\mathrm{H}$ sector. ${ }^{10}$

Once $e^{G *}$ is computed in the above procedure, the next step is to compare the level of social welfare between the two cases, namely $e^{G}=0$ and $e^{G}=e^{G *}$, and determine which policy choice is better and optimal for the government. Define the social welfare in each case as $U^{0}$ and $U^{*}$, respectively. Then, we have

\footnotetext{
${ }^{9}$ Note that there must exist $e^{G}$ which satisfies $\partial U / \partial e^{G}<0$ somewhere at large values because we assume $f^{\prime}(\underline{G})=$ $\infty$ at some $\underline{G}>0$. This implies that there does not exist the other corner solution where the government continues to inject capital into the bank until the capital constraint becomes slack (i.e., the point where the Lagrange multiplier $\lambda$ reaches zero).

${ }^{10}$ Note that the result that halfway recapitalization is not optimal may depend on the static structure of the model. If the dynamic optimization is introduced into the model, halfway recapitalization may be justified as an interim stage of capitalization.
} 


$$
U^{0}=Y^{0}+\alpha y_{l}^{0}+\beta f(T) \text { and } U^{*}=Y^{*}+\beta f\left(T-e^{G *}\right)
$$

where $Y^{0}$ and $Y^{*}$ are aggregate output realized in the second stage under $e^{G}=0$ and $e^{G}=e^{G *}$, and $y_{\text {low }}^{0}$ is the L sector's output under $e^{G}=0$. Note that since NPLs are fully resolved and $x=$ 1 under $e^{G}=e^{G *}$ as is claimed above, we have $y_{l}^{*}=0$. Then, the government will choose the zero recapitalization, $e^{G}=0$, if

$$
U^{0}-U^{*}=\left(Y^{0}-Y^{*}\right)+\alpha y_{l}^{0}+\beta\left\{f(T)-f\left(T-e^{G *}\right)\right\}>0,
$$

and choose, $e^{G}=e^{G *}$, if $U^{0}-U^{*}<0$.

As is clear from the above equation, the political economy equilibrium suggests that the optimal level of recapitalization by public funds depends on some key parameters in social welfare function as follows. First, the government does not have incentive to recapitalize the banking sector by public funds when the value of $\alpha$ and/or $\beta$ is high. In other words, recapitalization using public funds will not take place and the government choose the zero-capitalization policy if: (i) the government has special interests to help the L sector, namely SOEs, (i.e., high $\alpha$ ), or (ii) the government considers other government expenditures including infrastructure and social security as more important expenses than recapitalization of the banking sector, (i.e., high $\beta$ ). Second, the political economy equilibrium implies that when the government has a relatively large fiscal space (i.e., when $T$ is high), the government tends to conduct recapitalization using

public funds. This result comes from the fact that $\partial\left(U^{0}-U^{*}\right) / \partial T=f^{\prime}(T)-f^{\prime}\left(T-e^{G *}\right)<0$ due to the concavity of $f(G)$ (i.e., $f^{\prime \prime}(G)<0$ ). Hence, sufficient fiscal space is also a key factor for the government to carry out recapitalization using public funds.

\section{CONCLUSION ANd Policy Implications}

This paper first shows some empirical evidence for credit misallocation between SOEs and nonSOEs in Vietnam, and then theoretically discuss the extent of bank recapitalization and its effects on credit misallocation from a political economy viewpoint. The political trade-off for recapitalization reflect the following three things: the extent of the government's concern (special interest) for the favored, low-productivity sector, the relative importance across fiscal expenditures (infrastructure, education, social benefits, etc. vs. bank recapitalization), and the tightness of its fiscal space. Hence, bank recapitalization using public funds may be the selected policy response depending on an array of factors. The first-best, consisting of fast NPL resolution and full recapitalization by public funds, raises the quality of credit allocation and growth relative to the second-best, recapitalization using no public funds but using only banks' their own retained earnings. The first-best requires a government budget that is not too tight 
(marginal cost of funds below a certain threshold), highlighting the importance of fiscal space for financial stability.

A big caveat for the theoretical analysis is that recapitalization is not a sufficient condition for resolving credit misallocation but just one of necessary conditions for it. The model takes it as given that with enough capital buffers, banks would act properly and resolve credit misallocation by shutting down underperforming SOEs immediately. In reality, however, banks face many other constraints for doing it in addition to the thin capital buffers, such as political connections associated with underperforming SOEs, the lack of law enforcement for NPL resolution, and so on. Therefore, to resolve the problem of credit misallocation, those other constraints should be resolved at the same time, along with providing sufficient capital buffers through recapitalization. 


\section{References}

Dollar, David and Shang-Jin Wei (2007): “Das (Wasted) Kapital: Firm Ownership and Investment Efficiency in China," IMF Working paper, 07/9

Freixas, Xavier and Rochet J. C. (2008): Microeconomics of Banking, The MIT press

Hsieh, Chang-Tai, and Peter J. Klenow (2009): "Misallocation and Manufacturing TFP in China and India," Quarterly Journal of Economics, 124(4), 1403-1443

Gianetti, Mariassunta, and Andrei Simonov (2013): “On the Real Effects of Bank Bailouts: Micro Evidence from Japan," American Economic Journal: Macroeconomics, 5(1), 135 167

Grossman, Gene, and Elhanan Helpman (2001): Special Interest Politics, The MIT Press

International Monetary Fund (2013): Vientnam - Financial System Stability Assessment

International Monetary Fund (2016): The People's Republic of China -- 2016 Article IV Staff Report

Jobst, Andreas, Anna Ilyina, Dermot Monaghan, Dmitriy Kovtun, Jose M Garrido, Kenneth H Kang, Marina Moretti, Shekhar Aiyar, Wolfgang Bergthaler and Yan Liu (2016): “A Strategy for Resolving Europe's Problem Loans," IMF staff discussion notes, 15/19

Peek, Joe and Eric S. Rosengren (2005): "Unnatural Selection: Perverse Incentives and the Misallocation of Credit in Japan," American Economic Review, 95(4), 1144-1166

Maliszewski, Wojciech, Serkan Arslanalp, John Caparusso, José Garrido, Si Guo, Joong Shik Kang, W. Raphael Lam, T. Daniel Law, Wei Liao, Nadia Rendak, Philippe Wingender, Jiangyan Yu, and Longmei Zhang (2016): "Sharing China's Bank Restructuring Bill," IMF working paper, 16/203

Ma, Guonan (2006): "Resolving China's Corporate Debt Problem," China and World Economy, 14(3), 19-37

Song, Zheng, Kjetil Storesletten, and Fabrizio Zilibotti (2011): “Growing Like China," American Economic Review, 101(1), 196-233 